\title{
NOTAS ACERCA DE LOS DISPOSITIVOS DE PODER EN LA SOCIEDAD COLONIAL-FRONTERIZA, LA RESISTENCIA Y LA TRANSCULT,URACIÓN DE LOS RECHE-MAPUCHE DEL CENTRO-SUR DE CHILE (XVI-XVIII)
}

POR

\author{
GUILLAUME BOCCARA
}

Casa de Velázquez (EHEH)

Los mapuche o araucanos del centro-sur de Chile son célebres por la plurisecular resistencia que opusieron al invasor español en su voluntad de dominar la frontera sur del Tahuantinsuyu. Esta imagen tradicional del indio indómito, valiente y guerrero y de la Colonia como periodo de guerra permanente ha sido objeto de crítica por parte de los Estudios Fronterizos. Esta corriente historiográfica propuso una nueva visión del "encuentro" hispano-indigena que tomara en cuenta las relaciones fronterizas. Se muestra, sin embargo, que en su afán de escapar al paradigma de la guerra permanente, esta corriente ha caido en otro escollo que consiste en hablar de paz cuando parece más ajustado hablar de cambios en los dispositivos de poder, y asimismo ha dejado escapar la principal consecuencia del contacto hispano-indigena, a saber: la gestación de una nueva entidad e identidad étnica a través de un largo proceso de etnogénesis que nos hace pasar de los reche del siglo XVI a los mapuche del siglo XVIII.

Abordaremos aquí dos problemas relacionados entre sí sobre el tema de la interacción histórica entre los indígenas del

SigLAS UTILIZADAS:

AFC: Archivo Franciscano de Chillán.

BNCH: Biblioteca Nacional de Chile, Santiago.

MM: Manuscritos Medina. 
centro-sur de Chile y los españoles (1). Como bien sabemos los que trabajamos sobre la historia de los mapuche, si bien es cierto que la bibliografía sobre el tema es bastante amplia, quedan todavía muchos problemas básicos por resolver $\mathrm{y}$, sobre todo, existen muchas ideas tenidas por ciertas y que -como veremos- no lo son.

La primera afirmación que se tiene por cierta es que, a la llegada de los españoles, había mapuche o araucanos en el centro-sur de Chile, es decir en la Araucanía. Veremos que, si bien es cierto que había habitantes en esos territorios, no se llamaban ni mapuche ni araucanos, sino reche.

Aclaremos primero un punto: los araucanos eran los indígenas que pertenecían al ayllarewe (2) o parcialidad de Arauco

(1) Las propuestas que, por razones de espacio, presentamos aquí de manera muy escueta y a modo de avance son fruto de una investigación más amplia, que vinimos haciendo desde hace varios años con miras a realizar una tesis doctoral (en fase de redacción). Mi agradecimiento a los investigadores del Departamento de Historia de América del CSIC, en donde presenté estas ideas, y particularmente a Carlos LÁZARO Ávila. Agradezco también a Eugenia NEVES, Silvia GALINDO y Leonardo LEÓN Solís, quienes me ayudaron en mi investigación en Chile, así como a Ingrid SEguel-Boccara y a Berta ARES por su lectura crítica y a Stephane ANGLES por la realización de los mapas.

(2) La palabra ayllarewe significa nueve (aylla) rewe (re: puro, autëntico, we: lugar). El ayllarewe era el agregado socio-político mayor, que agrupaba varios rewe en período de guerra. El rewe constituía la unidad socio-política objetiva y subjetivamente central de la forma social reche. Cada rewe tenía un "jefe» de guerra (gentoqui) y un «jefe» de paz (genvoye), y disponía de un espacio ceremonial propio (llamado también rewe) y de un lugar para la realización de las juntas militares (lepún). Las decisiones tomadas en el rewe debían ser respetadas y la violación de la «ley» (homicidio, adulterio, robo) estaba sometida a compensación. Esta unidad política, independiente y autónoma, puede ser considerada como el primer nivel de la demarcación identitaria entre el sí mismo y el otro. Se ha escrito que el rewe era el clan y el ayllarewe la tribu, pero esta visión de la sociedad reche como estructura segmentaria corresponde más a la aplicación errónea de categorías antropológicas construidas en otros contextos y áreas que a la realidad sociológica reche. En efecto, el rewe agrupa a varias parentelas, organizadas alrededor de un gran hombre o ulmen; de tal suerte que el rewe (que aparece también en los títulos de encomienda como equivalente al $l e b o$ ) no es en ningún caso un grupo de unifiliación. Señalemos finalmente que el término futamapu que utilizaremos en este artículo y que significa tierra (mapu) grande (futa), es un agregado político que agrupaba a varios ayllarewe. El territorio reche estaba dividi- 
y que fueron casi los primeros en oponer una resistencia feroz a los conquistadores. A partir de esta confrontación prolongada, los españoles (y sobre todo uno: Alonso de Ercilla, el famoso autor de La Araucana) aplicaron el término de araucano a todos los habitantes que vivían más al sur de Arauco. Notemos también que incluso los propios españoles hablaban raramente de los araucanos para designar a todos los habitantes de la Araucanía. Esta precisión va mucho más allá de una simple cuestión de vocabulario, ya que -como vamos a ver-decir que había mapuche o araucanos en el centro-sur de Chile, en el siglo XVI, es dejar escapar el mayor acontecimiento y el principal resultado de los tres siglos de contactos y confrontación hispano-indígena, a saber, la emergencia de una nueva entidad e identidad étnica, a través de un largo proceso de etnogénesis, que nos hace pasar de los reche del siglo Xvi a los mapuche de la segunda mitad del siglo XVIII y que aún perviven hoy en día.

Además y sin ser demasiado positivistas, creemos que hablar de mapuche en los siglos xvi y XVII, cuando la palabra no aparece ni una sola vez en los documentos, demuestra una férrea voluntad de hablar de algo que no existe o de no hablar de algo que quizá existió. Es decir que, cuando se habla de mapuche para los siglos XVI y XVII, o se demuestra una ceguera extraordinaria en la lectura de los documentos, en los que -repito- nunca aparece la palabra citada, o se demuestra una extraña negligencia en no averiguar el hecho de que los espa-

\footnotetext{
do en tres futamapu que iban de norte a sur: el lavquenmapu (tierra grande de la mar o costa), el lelfünmapu (tierra grande de los llanos) y el inapirema$p u$ (tierra grande del piedemonte de los Andes). Existen también muchas confusiones sobre lo que representaba este agregado; algunos estudiosos afirman, de manera equivocada, que es una intervención de los españoles para dividir más claramente el territorio reche; otros afirman que es de origen reche, pero que aparece sólamente en la segunda mitad del siglo XVII. Lo que aquí podemos afirmar es que el futamapu es un agregado socio-político reche que existía desde principios del siglo XVII y cuyas características fueron cambiando a lo largo del período colonial. No es, pues, el fruto de la imaginación de los españoles, pero tampoco es seguro que sea una institución postcolombina. Lo que sí es seguro es que este agregado (como el rewe y el ayllarewe) cambió en el proceso de reestructuración de la sociedad reche, tal y como lo veremos en este trabajo.
} 
ñoles no hablen de mapuche si efectivamente estamos seguros de que existían entonces.

No menospreciamos, desde luego, la comodidad que supone utilizar una denominación, mapuche o araucano, que todo el mundo conoce, en vez de la desconocida de reche. Tampoco subestimamos el peso de la costumbre, ya que hace muchos años que se habla de mapuche o araucano. Además, hay que tener en cuenta las proyecciones de una realidad presente, la minoría étnica mapuche actual, sobre el pasado. Pero a pesar de todos esos inconvenientes creemos necesario emprender una crítica minuciosa de esas prácticas cómodas porque, detrás de la evidencia y de la aparente neutralidad de la utilización de tales términos, se vislumbra un visión esencialista o sustancialista de los fenómenos sociales y culturales. Dicho en otros términos, afirmar o dar por hecho que había mapuche en el siglo XVI quiere decir que esta entidad étnica siempre ha existido. Sin embargo, veremos que los mapuche, como todos los pueblos y naciones, son el resultado de una historia. La entidad e identidad étnica mapuche son un producto, una construcción histórica, que surgieron del profundo proceso de cambio en las estructuras objetivas y subjetivas de las comunidades reche.

El segundo punto que abordaremos tiene que ver con lo que podríamos llamar la evolución de los dispositivos de poder establecidos por los españoles para someter y dominar al indígena. En esta ocasión discutiremos las proposiciones de la corriente historiográfica llamada de los Estudios Fronterizos, que se desarrolló en Chile durante los años 80 (3). Veremos que, si bien los historiadores de esta corriente nos permiten

(3) Sus representantes más notables son: Sergio Villalobos, Jorge Pinto Rodríguez, Horacio Zapater, Luz María MÉndez, Holdenis CaSanova, Carlos AldUNATE DEL Solar. Entre las obras más características de los Estudios Fronterizos se pueden mencionar: Sergio VIllalobos y otros, Relaciones fronterizas en la Araucania, Santiago, Universidad Católica de Chile, 1982; Holdenis CASANOVA, Las rebeliones araucanas del siglo XVIII, Temuco, Ediciones Universidad de La Frontera, 1987; Jorge PINTo Rodríguez y otros, Misioneros en la Araucanía 1600-1900, Temuco, Ediciones Universidad de la Frontera, 1988, y Sergio Villalobos y Jorge Pinto RodRíguez (Compiladores), Araucania, temas de historia fronteriza, Temuco, Ediciones Universidad de la Frontera, 1989; Sergio Villalobos, La vida fronteriza en Chile, Madrid, Ed. Mapfre, 1992. 
salir del mito de la guerra permanente entre indígenas y españoles, con el fin de interesarse por los problemas de frontera y de intercambios culturales, sus propuestas y el marco interpretativo en el que se desarrollan son bastante discutibles. Trataremos de demostrar que la afirmación según la cual, después de un período de guerra de cien años entre españoles e indígenas, se asentó un período de paz fronteriza, resulta ser -bajo nuestro punto de vista- equivocada en el sentido de que, aunque no hubo una guerra permanente a lo largo del período colonial, parece más ajustado hablar de un cambio por parte de los españoles en las técnicas de sometimiento y de dominación. Veremos además que no hubo asimilación progresiva de los indígenas a la supuesta superioridad cultural europea, como afirma Sergio Villalobos, sino que fue prácticamente todo lo contrario.

\section{1. ¿QUIÉNES SON LOS MAPUCHE?}

En esta parte quisiéramos presentar rápidamente lo que se ha escrito sobre la población que vivía en el centro-sur de Chile a la llegada de los españoles. Tomaremos el ejemplo de algunos historiadores y antropólogos que han marcado la historia de los estudios araucanos como Tomás Guevara, Ricardo Latcham (autores de principios de siglo), Luis Faron, Carlos Aldunate, Osvaldo Silva y Adalberto Salas, estudiosos del momento actual.

Según Guevara, rector del colegio de Temuco y gran conocedor de la realidad mapuche post-reduccional, el territorio situado entre el río Copiapo y el seno de Reloncaví estaba habitado en el siglo XVI por la etnia mapuche, que se dividía en cuatro grandes regiones: los picunches (Copiapo-Rapel), los promaucaes (Rapel-Itata), los araucanos (Itata-Tolten) y los huilliches (Tolten-seno de Reloncavi) (4).

Para Latcham, autor de numerosos estudios de etnología sobre los mapuche, muy influenciado por las teorías evolucionistas de su época y también gran conocedor de la realidad

(4) Tomás Guevara, Chile Prehispano, 1925, Santiago, Chile. 
mapuche post-reduccional, la población que vivía en el centro y centro-sur de Chile a la llegada de los conquistadores se dividía así: los picunches al norte del río Bío-Bío, los mapuches o araucanos entre los ríos Bío-Bío y Tolten, y los huilliches hasta el archipiélago de Chiloé (5).

Por su parte Louis Faron, antropólogo norteámericano y autor de numerosos estudios sobre los mapuche del siglo $\mathrm{xx}$, los araucanos representan una población más amplia que los mapuche. A la llegada de los españoles tendríamos a los picunches araucanos del norte, a los mapuches araucanos del centro y a los huilliches araucanos del sur. Faron retoma, por tanto, la repartición étnica de Latcham pero no asimila los araucanos a los mapuche. Según él, tendríamos una entidad cultural heterogénea, los araucanos, que abarcaría a tres grandes etnias: picunches, mapuches y huilliches (6).

Según Osvaldo Silva, prehistoriador y antropólogo chileno, la repartición de Tomás Guevara es aceptable siempre y cuando se añada una quinta región entre los ríos Maule e Itata. Para él, los araucanos son un conjunto de tribus que forman parte de una entidad más amplia: la etnia mapuche (7).

En resumen, mientras que para Faron los mapuche son los que forman parte de una entidad mayor llamada Araucana, para Silva y Guevara son los araucanos quienes forman parte de una unidad étnica más amplia, que posee un idioma y una cultura común: la etnia mapuche. Recordemos que Latcham identificaba mapuche con araucano.

Por último, para Carlos Aldunate, arqueólogo y antropólogo chileno, el territorio ubicado al sur del río Maipo estaba poblado por los auca o purum-auca, término quechua que designa a los rebeldes, los enemigos salvajes. Esta denominación fue reto-

(5) Ricardo LATCHAN, La organización social y las creencias religiosas de los antiguos araucanos, Santiago, Chile, 1924. La prehistoria Chilena, Santiago, Chile, 1928.

(6) Louis FARON, "Araucanian Patri-Organization and the Omaha System» en American Anthropologist, vol. 58, núm. 3, junio 1956, págs. 435-456.

(7) Osvaldo Silva, "En torno a la estructura social de los mapuches prehispánicos", en Cultura, Hombre y Sociedad, 1, Santiago, 1984, págs. 89-115. "Los Araucanos prehispánicos. ¿Un caso de doble filiación?» en Boletín del Museo Regional de Araucanía, Temuco, 1984, núm. 1, págs. 41-46. 
mada por los conquistadores que los llamaron purum-aucaes, indios aucaes de Chile o simplemente aucas (8).

Detengámonos un instante aquí antes de ver lo que dice de esta cuestión Adalberto Salas, etnolingüista chileno, porque sus afirmaciones se diferencian bastante de las de los anteriores, y porque queremos retomar el problema que reflejan estas contradicciones en la delimitación del territorio de Chile en cuanto a los diversos habitantes que vivieron en él.

Comencemos por una constatación sencilla y básica: todos los autores mencionados reconocen, más allá de sus discrepancias, que entre los ríos Bío-Bío y Tolten había una población que, tanto por sus rasgos culturales como por su modo de organización y su carácter belicoso, se diferenciaba de sus vecinos del norte, del sur y del este.

Ahora bien, vayamos con los estudiosos que los llaman mapuche (Faron, Latcham, Aldunate). Si consideramos las fuentes de los siglos xVi y xvir, e incluso podríamos incluir las de la primera mitad del siglo xVIII, tanto en los documentos de archivo como en las crónicas o historias de Chile nos enfrentamos a un problema bastante considerable: ila palabra mapuche no aparece nunca!

Como señalamos en la introducción creemos que, sin ser demasiado positivistas, a la hora de realizar un trabajo histórico mínimamente riguroso debemos preguntarnos por qué las palabras picunches, huilliches, puelches y pehuenches aparecen en los documentos para designar grupos étnicos en apariencia territorialmente localizados, y sin embargo la población ubicada entre los ríos Bío-Bío y Tolten nunca aparece mencionada bajo la palabra mapuche.

No decimos, por el momento, que la población que vivía entre esos dos ríos no se denominara a sí misma mapuche; constatamos simplemente que la palabra nunca aparece, cuando las otras sí, y que por tanto es imposible decir, en un trabajo de

(8) Carlos Aldunate, "El indígena y la frontera» en Sergio Villalobos y otros [3], 1982. "Estudio alfarero en el sur de Chile. (500 a ca. 1800 d.C.)", en Prehistoria, Jorge Hidalgo y otros, Santiago, editorial Andrés Bello, 1989, págs. 329-348. 
carácter histórico, que la etnia mapuche vivía a la llegada de los españoles entre esos dos ríos.

Vayamos ahora con los estudiosos (Guevara y Silva) que afirman que la población que habitaba entre los ríos Itata y Tolten se denominaba araucano. Aquí tenemos un problema distinto, incluso inverso, al que enfrentamos anteriormente. La palabra araucano aparece efectivamente en la literatura colonial para designar a una población belicosa radicada al sur del río Bío‘Bío. Además, como hemos mencionado en la introducción, la palabra aparece muy tempranamente puesto que a la llegada de los españoles se refieren ya a la provincia de Arauco. Por otra parte, la palabra araucano aparece en muchos documentos.

Ahora bien, sabemos con certeza que la palabra arauco, que según Diego de Rosales significa «agua de greda» (Rag-co), se refería a un territorio estrictamente limitado que comprendía las distintas comunidades (rewe) de la provincia (ayllarewe) de Arauco (9). Los mismos españoles hacían la diferencia entre los llamados araucanos y los otros grupos de indígenas: tucapelinos, catirayes, maquehuanos, etc.

En fin, mientras que algunos estudiosos ven mapuche donde no existen, víctimas involuntarias de su mirada del siglo $\mathrm{xx}$, en el que la autodenominación mapuche está establecida, otros autores extienden una denominación (araucano), empleada de manera errónea por algunos españoles de la época colonial, al conjunto de los habitantes que poblaban el territorio situado entre los ríos Bío-Bío y Tolten.

Nos hemos permitido detenernos sobre estas contradicciones entre los diferentes estudiosos porque pensamos que detrás de ellas se puede percibir uno de los pecados capitales, en el sentido de que manchan irremediablemente la investigación ulterior, de una gran parte de la literatura histórica y antropológica sobre los mapuche; a saber: considerar a una etnia como una sustancia, como algo que ya está dado, como una esencia que existiría in se y per se. Este largo esclarecimiento era por consiguiente necesario para poder abordar a continuación lo que consideramos un proceso de etnogénesis.

(9) Sobre las categorías rewe y ayllarewe véase la nota 2 de este trabajo. 
La pregunta que debemos hacernos es obvia: Si en el siglo XVI no había una población que se autodesignase mapuche ni se percibiese como tal, ni mucho menos había araucanos en tanto etnia, ¿qué había entonces?

Retomemos al respecto nuestra presentación de los diferentes estudiosos para llegar a Adalberto Salas. Este etnolingüista publicó un libro sobre el idioma mapuche (10), en el cual dedica un breve capítulo a la presentación histórica de esta población. Aunque el estudio trata fundamentalmente del mapudungun se puede considerar que, a través de las pocas páginas dedicadas a la antropología histórica de los habitantes del centro-sur de Chile, este trabajo marca un hito dentro de la etnohistoriografía mapuche. En efecto, Salas pone en tela de juicio la utilización por parte de los antropólogos e historiadores de las palabras picunche, huilliche y mapuche, y hace referencia a un artículo del arqueólogo chileno Américo Gordon, quien señala que la palabra mapuche como denominación étnica empieza a utilizarse solamente a partir de la segunda mitad del siglo xIX (11).

He aquí lo que escribe Salas:

Se estima que en el siglo XVI la población autóctona del reino de Chile ascendía al millón de personas; la mayor parte (unas 600.000) se concentraba entre los ríos Bío-Bío y Tolten. No hay indicios de que esta población tuviese un nombre específico para autodenominarse, pero es plausible concebir que dada la necesidad autoidentificatoria en oposición a extranjeros invasores, recurrirían ocasionalmente a frases como reche "gente de verdad, gente auténtica" o a compuestos como mapu-che "gente autóctona, gente del país», de mapu "tierra, país» y che "persona», usado no como nombre específico de grupo étnico, sino más bien como una categoría amplia de personas: «los nativos». A medida que el contacto externo fue incrementándose, la necesidad terminológicamente

(10) Adalberto SALAS, El Mapuche o Araucano, fonología, gramática y antologia de cuentos, Madrid, Editorial Mapfre, 1992.

(11) "Consideraciones sobre el significado de la palabra 'mapuche'», Actas. Jornadas de Lengua y Literatura Mapuche, Temuco, Universidad de La Frontera e Instituto Linguístico de Verano, 1984, págs. 41-50. 
fue haciéndose mayor, hasta que a finales del siglo XIX, la palabra mapuche se asentó definitivamente como denominación autoidentificatoria del grupo (12).

Y sigue después:

En la literatura antropológica e histórica, se ha genèralizado el uso de la palabra picunche para referirse a la población mapuche (...) radicada a la llegada de los españoles en las tierras al norte del Bío-Bío, en particular entre el valle del río Mapocho y el río Maule. Está formada a partir del compuesto pikum-che "gente del norte» (pikum "norte» y che "gente»). No hay buenos indicios de que pikumche tenga o haya tenido el significado que le han dado los antropólogos e historiadores. Fue y es sólo un deíctico (como el castellano "nortino») y no el nombre de una parcialidad o subdivisión de los mapuches, internamente percibida como tal (13).

Citaremos finalmente otra parte de este pequeño, pero importantísimo, capítulo del libro de Salas en la que trata del término auca o purum-auca:

Los soldados y funcionarios del imperio incaico llamaban purum awka "enemigo salvaje, enemigo en rebeldía», o simplemente awka "gente o animal salvaje», a los grupos extranjeros que no podían pacificar e incorporar a la estructura sociopolítica imperial. En Chile aplicaron estas denominaciones a los nativos hostiles que encontraron entre los ríos Maule y Bío-Bío. Entre los historiadores y antropólogos, circula a veces el derivado hispánico promauca (y variantes) como nombre de un presunto grupo étnico asentado en esa área, lo que es inexacto: entre el Maule y el Bío-Bío vivían mapuches no sometidos al incanato y complementamente absorbidos en la hispanidad durante la Colonia. (14).

En el mismo capítulo Salas critica también la utilización del término huilliche para designar a la población ubicada al

(12) SALAS [10], págs. 29-30.

(13) Ibidem, pág. 30

(14) Ibidem. 
sur del río Tolten. En efecto, huilliche es como pikumche en deíctico.

Vemos que Salas, aunque no aporte solución al problema y continúe hablando de mapuche, a pesar de que la palabra no aparezca en los documentos, realiza una crítica bastante convincente de los términos empleados por los historiadores y antropólogos a la hora de designar a las poblaciones indígenas del centro y centro-sur de Chile. Al final de su capítulo, de manera quizá un poco irónica, escribe:

Las denominaciones examinadas (y otras similares) corresponden a distinciones hechas por los académicos a partir de necesidades derivadas de sus propias disciplinas, que no se vinculan a subgrupos étnicos mapuches definibles por criterios internos a la sociedad mapuche (15).

Finalmente hay que señalar que, además de Salas, el estudioso que ha sido más claro sobre esta cuestión es seguramente Horacio Zapater cuando dice:

Los vocabularios de los tres misioneros jesuitas (Valdivia, Febres, Havestadt) demuestran que, en los siglos XVII y XVIII, los indígenas se autodenominaban reche. La voz mapuche debe provenir del siglo XIX al enfrentar el aborigen el problema de la usurpación de sus tierras (16).

El trabajo que hemos realizado sobre los documentos de los siglos XVI, XVII y XVIII confirma totalmente las críticas y dudas emitidas por Adalberto Salas y Horacio Zapater. Además, hemos podido llegar a establecer algunas conclusiones, que se pueden resumir en dos puntos esenciales.

Primero, en el siglo XVI las poblaciones situadas entre los ríos Itata y Tolten tienen una organización socio-política diferente de sus vecinos del sur y del norte. Los títulos de encomienda de los primeros años de la conquista muestran una

(15) Ibidem, págs. 31-32.

(16) Horacio ZaPATER, La búsqueda de la paz en la guerra de Arauco: Padre Luis de Valdivia, Santiago, editorial Andrés Bello, 1992, pág. 106, nota 50. 
diferencia notable en el vocabulario utilizado para designar los distritos, parcialidades o provincias indígenas de esas tres zonas. Las tres poblaciones se diferencian grandemente en la resistencia que opusieron a los invasores. Los habitantes situados entre los rios Itata y Tolten son, para decirlo rápidamente, mucho más guerreros. Los reche, término que utilizaremos a partir de ahora -de hecho ellos mismos se llamaban así, según escribe el jesuita Luis de. Valdivia en su diccionario (17)-, tenían relaciones de dominación con las poblaciones situadas más al sur del río Tolten. Además, parece que esos vecinos designaban también a los reche como aucaes y que veían en ellos a unos vecinos peligrosos. Finalmente, está confirmado que los términos picunche y huilliche son deícticos, ya que en los documentos hemos encontrado a los picunches y huilliches ubicados al sur del río Bío-Bío.

La segunda conclusión a la que hemos llegado es que la etnia mapuche es un producto histórico surgido de las transformaciones objetivas y subjetivas, que tuvieron lugar entre las comunidades reche de los siglos XVI y XVII. Es decir, si bien en esos dos siglos nos encontramos en presencia de comunidades autónomas e independientes de araucanos, tucapelinos, maquehuanos, catirayes, etc., que representan el agregado sociopolítico mayor, poco a poco se produce un proceso de cristalización política, que conduce a un cambio de escala en la toma de decisiones esenciales al porvenir de la comunidad. Para ser más preciso diré que, mientras que en los siglos XVI y XVII la unidad socio-política objetiva y subjetivamente fundamental es el rewe o lebo, a partir del siglo xviII es el ayllarewe el que pasa a ser la unidad central de la «socialidad» reche.

Además hay que señalar que este proceso de cristalización socio-política se produce a un nivel superior con la institucionalización de los tres grandes territorios que dividen el espacio reche, a saber los futamapu. Porque si bien en los dos primeros siglos de la época colonial esta división no funciona plenamente como estructura socio-política permanente y claramente de-

(17) Luis de Valdivia, Arte y Gramática General de la lengua que corre en todo el Reino de Chile, en Lima, por Francisco del Canto, año 1606, edición facsimilar de Julio Platzmann, Leipzig, 1887. 
finida, a partir del siglo xvIII vemos ya aparecer este agregado socio-político como instancia macro-regional de decisión y de estructuración del espacio político. Tenemos entonces un primer cambio en las estructuras objetivas, materiales, de organización socio-política, que se expresa a través de la cristalización de unidades antes claramente separadas y totalmente independientes. Este proceso de coagulación tiene como consecuencia un cambio en los mecanismos tradicionales de la representación política.

A nivel material, tenemos también un doble cambio económico patente en el siglo xviII, pero que ya se dejaba vislumbrar en el XVII. Primero, un enriquecimiento sin precedentes de los caciques o ulmen. Segundo, la expansión de los grupos reche allende la cordillera, la llamada araucanización de la Pampa. Se podría decir que este último fenómeno es la máxima consecuencia de la adopción del caballo por los reche. Y justamente la integración muy temprana del caballo en la sociedad reche, al permitir una mayor movilidad, cambió las relaciones entre comunidades y operó como factor de unificación identitaria (18).

Así pues, a partir de un momento nos encontramos ante estructuras políticas y económicas macro-regionales que no existían en los siglos xVI y xVII. Pero es más, a nivel ideológico, tenemos la aparición de una entidad religiosa única, ngenechen, que no existía en los siglos anteriores y que tiene un carácter macro-regional.

Todos estos cambios, que aparecen masivamente en el siglo XVIII, no podían dejar de tener consecuencias a nivel de la definición de la propia identidad. Dicho en otras palabras, los cambios en las estructuras objetivas y subjetivas tuvieron lógicamente consecuencias a nivel de la identidad y en la manera de percibirse como grupo diferenciado, dotado de estructuras socio-políticas macro-regionales. Es precisamente en esté contexto de transformaciones y reestructuraciones en donde surge la palabra mapuche, pues la hemos encontrado mucho antes de lo que dice Américo Gordon, entre otros investigadores. Para

(18) El antropólogo chileno Arturo LeIva trata de este tema en su estudio intitulado: "La araucanización del caballo en los siglos XVI y XVII" Anales Temuco, Universidad de La Frontera, 1981-1982, págs. 181-203. 
ser más exacto, la palabra mapuche aparece en la segunda mitad del siglo xviI, justo en la época en la que se asientan y se afianzan los nuevos mecanismos sociales de la nueva entidad étnica mapuche (19).

Sería muy largo dar más pormenores sobre este proceso de etno-génesis. Pero lo que hemos querido mostrar en esta primera parte es que, detrás de los problemas de vocabulario, se esconden a veces cuestiones más esenciales que, como en éste caso, tienen que ver con el surgimiento de una etnia. Se podría decir que, lejos de haber dominado y sometido a los indígenas, los españoles pusieron en marcha una dinámica de cambios tremendos que condujeron a la génesis, a la construcción histórica y a la aparición de una nueva etnia: los mapuche. Esto constituye un caso abrumador de lo que se podría llamar efectos perversos de la Conquista, en el sentido de efectos no queridos, no esperados. Es además una ilustración interesante de aquella frase de Marx que decía: "los hombres hacen su propia historia, pero no saben que la hacen", idea que según LeviStrauss «justifica, en su primer término, la Historia, y en su segundo tiempo la Etnología, y a la vez demuestra que las dos disciplinas son indisociables". Y de hecho, lo que ha faltado en el estudio del caso mapuche es la perspectiva que nos puede dar la etnohistoria o antropología histórica.

2. DisPositivos DE PODER EN LA SOCIEDAD

COLONIAL-FRONTERIZA (XVI-XVIII).

REVISIÓN DEL MARCO INTERPRETATIVO DE LOS

ESTUDIOS FRONTERIZOS

En esta segunda parte queremos abordar el tema de la Conquista y colonización de Chile bajo un enfoque político. Esto ho implica una descripción del funcionamiento de las distintas instituciones políticas o la aprehensión de la historia colonial a partir de las múltiples cédulas reales, sino que qui-

(19) Además de en otros documentos que hemos visto, la palabra aparece en el libro del misionero jesuita Andrés FEBREs, Arte de la lengua general del reyno de Chile..., Lima, 1765.

R. I., 1996, n.॰ 208 
siéramos abordar el problema del encuentro o «mal encuentro» desde lo que M. Foucault llama una microfísica del poder. Trataremos de desarrollar una reflexión en torno al concepto de paz en los Estudios Fronterizos y propondremos un marco interpretativo de los dispositivos de poder y sometimiento que nos parece más acertado.

En primer lugar, daremos a conocer las herramientas teóricas que hemos utilizado para luego presentar lo que hemos denominado «los dispositivos de poder en la sociedad colonialfronteriza» durante los siglos XVI, XVII y XVIII. Aunque no podremos entrar aquí en muchos pormenores, elegiremos algunos documentos y acontecimientos característicos de ese tiempo.

\subsection{Poder y dispositivos de poder según Michel Foucault}

Aquí haremos uso de algunas proposiciones teóricas con respecto al poder que propone el filósofo francés Michel Foucault. Este autor criticó la definición tradicional de poder como sustancia o materia que poseerían algunos grupos o individuos para utilizarlo, por medio de la violencia o represión, con el fin de imponer su voluntad. Esta concepción se fundamenta en lo que Gilles Deleuze (20) enunció como los postulados de propiedad, localización, subordinación, esencia o atributo, modalidad y legalidad, que podríamos resumir así:

1. Postulado de propiedad: el poder se apropia.

2. Postulado de localización: el poder es un poder de Estado.

3. Postulado de subordinación: el poder encarnado en el aparato del Estado está subordinado a un modo de producción.

4. Postulado de esencia o atributo: algunos poseen el poder como se posee una riqueza.

5. Postulado de modalidad: el poder actúa por violencia o por ideología, a través de la policía o de la propaganda.

6. Postulado de legalidad: el poder de Estado se expresa en la ley.

(20) Gilles Deleuze, Foucault, París, Ed. de Minuit, 1986, págs. 31-37. 
Frente a esta concepción del poder, Foucault propone lo siguiente: «El poder no es ni una institución, ni una estructura, ni una determinada potencia de la cual algunos estarían dotados: sino que es la denominación que se le da a una situación compleja en una sociedad dada» (21). De este modo, el poder sería

la multiplicidad de las relaciones de fuerza inmanentes al espacio en el cual se ejercitan y son constitutivas de su organización; el juego que, por vía de luchas y enfrentamientos incesantes, las transforme, las refuerce, las invierta (...), las estrategias en las que cobran efecto, y cuyo fin general o cuya cristalización institucional toman cuerpo en los aparatos estatales, en la formulación de la ley, en las hegemonías sociales (22).

A partir de esto, se puede definir una multiplicidad de categorías de poder mucho más complejas que la de represión: incitar, inducir, desviar, hacer algo difícil o fácil, ampliar o limitar, hacer algo más o menos probable (23). La cuestión inicial, que buscaba determinar quién es el poseedor del poder, se transforma en la siguiente pregunta: ¿quién ejercita el poder?

Esta concepción del poder de Foucault nos permite ir más allá de una visión jurídico-política de la soberanía para encauzar el análisis «hacia la dominación, hacia los operadores materiales, las formas de sometimiento, hacia los dispositivos de estrategia... partiendo de las técnicas y tácticas de dominación» (24). De acuerdo a esto, estudiar un período histórico bajo un enfoque político consiste en definir los dispositivos concretos de poder y en determinar la lógica global en la que estos dispositivos se inscriben. Esta lógica global, que Foucault llama máquina abstracta o diagrama, funciona según un principio específico que difunde su tono a todos los dispositivos concretos de poder.

(21) Michael Foucault, Histoire de la sexualité, tomo 1, París, Gallimard, 1976, pág. 123.

(22) Ibidem, pág. 122.

(23) Deleuze [20], pág. 77.

(24) Michael Foucault, Microfísica del poder, Madrid, las ediciones de la Piqueta, 1992, pág. 147.

R. I., 1996, n. 208 
Para retomar el tema que nos preocupa, opinamos que en el siglo XVI y hasta más o menos la mitad del siglo xvir existió un diagrama soberano con dispositivos concretos de poder, tales como la encomienda, la expedición guerrera, la esclavitud, el requerimiento, la maloca y el fuerte; mientras que, a partir de la segunda mitad del siglo xVII y durante el siglo XVIII, se estableció un diagrama disciplinario materializado en los dispositivos de la Misión, el Parlamento, el comercio, la escuela de indios, la instauración de los caciques embajadores, etc.

\subsection{Periodización histórica}

Pensamos que la tecnología (término del propio Foucault) utilizada para someter a lo que se le dio el nombre de barbarie se modificó durante los casi tres siglos de la presencia española en Chile; de modo que si bien es justo hablar de 250 años de colonización, sería un profundo error considerarlos como un todo homogéneo. Y de hecho, este tipo de preocupación se ha venido desarrollando en Chile desde principios de los años ochenta bajo el nombre de Estudios Fronterizos. En efecto, se ha dicho que después de 100 años de guerra, se empezó a asentar en la frontera una red de relaciones entre las dos sociedades que generó una $\mathrm{paz}$, que algunos incidentes bélicos venían a turbar, generalmente por culpa de individuos sin escrúpulos o a causa de proyectos inoportunos (25).

(25) En su contribución al libro Araucania, temas de historia fronteriza [3], Sergio Villalobos escribe: «El cuadro sinóptico y la periodificación que hemos hecho, prueba que no solamente había desaparecido la guerra, sino que el sistema de relaciones fronterizas, en el correr de los siglos había producido una compenetración de los dos pueblos en todos los aspectos. Por esta razón resulta equivocado pensar que los araucanos debieron ser sometidos. Lo que hubo fue una asimilación y penetración espontánea, que determinaron muchos cambios en los indígenas y llevaron éstos a reducir su resistencia y, finalmente, a aceptar de alguna manera la intromisión hispana y chilena. No fue la lucha lo que determinó el sometimiento, sino una red de intereses comunes, en que cada uno sacaba ventajas para sí. Las armas habían fracasado mil veces; la paz, en cambio, fue el factor decisivo de la integración gradual» (págs. 29-30).

En otro de sus trabajos escribe: «Bajo el régimen republicano continuó la compenetración de chilenos y araucanos en una paz apenas interrumpida 
Sin embargo, aunque los Estudios Fronterizos permiten salir de la retórica tradicional de la guerra permanente y de la mito-

por estadillos pequeños y esporádicos, preparándose así la incorporación plena de la Araucanía" (Relaciones fronterizas en la Araucania, pág. 180).

Aunque no es éste el lugar para una crítica general de los presupueștos teóricos y prejuicios ideológicos de tales afirmaciones, hemos de esclarecer algunos puntos. En primer lugar, la Araucanía no se incorporó de manera pacífica al Estado chileno; José BENGOA ha mostrado en su Historia del pueblo Mapuche (Santiago, Ediciones Sur, 1985) que la llamada pacificación de la Araucanía, que tuvo lugar a principios de los años ochenta del siglo pasado, resultó ser extremadamente violenta y mortífera. En seguno lugar, el eufemismo utilizado a la hora de tratar del sometimiento de los mapuche y de su integración al Estado chileno no radica sólamente en la voluntad consciente de borrar una faceta negra de la historia de este país, sino que también es la expresión de una visión evolucionista y jerárquica de sociedades y culturas. Desde este punto de vista etnocéntrico, los araucanos como pueblo "primitivo" deben integrarse ineludiblemente a una sociedad culturalmente superior. Además, su atracción hacia los productos culturales occidentales es interpretada como la prueba abrumadora de su voluntad de asimilación. Clara expresión de esta concepción jerárquica de las culturas es esta frase del mismo VI. LLALOBOS: "la interminable serie de baratijas que el hombre civilizado proporciona a los pueblos de menor cultura" (Relaciones fronterizas en la Araucania, pág. 179). Hay varias cosas que señalar al respecto: primero, el hecho de asimilar productos ajenos a su cultura no significa entrar en un proceso de asimilación y dilución de la especificidad cultural. Nathan WACHTEL ha mostrado en sus trabajos sobre los procesos de aculturación que es necesario distinguir entre la aculturación impuesta y la aculturación espontánea (Cír. La vision des vaincus, Gallimard, París, 1971, "L'acculturation" en Faire de l'Histoire, tomo I, Gallimard, París, 1974). En el caso mapuche o reche estamos en presencia de un proceso de resistencia y aculturación espontánea (o antagónica), en el que los productos culturales ajenos son asimilados reinterpretados dentro del marco cultural tradicional. Además, demostramos en otro trabajo (La guèrrè reche comme fait social total, inédito) que no sólamente reinterpretan los productos ajenos a su cultura, sino que los necesitaban para reproducir su propia diferencia. De tal suerte que la sociedad reche funcionaba como un dispositvo de captación de la diferencia y que se podría definir la cultura reche como una cultura caníbal. Sin entrar en más detalles, pensamos que si los Estudios Fronterizos tienden a adoptar un punto de vista etnocéntrico es porque carecen totalmente de una perspectiva antropológica y que jamás han tomado en cuenta el lado indígena de la Conquista.

Hay que señalar finalmente que la perspectiva antropológica no debe limitarse al lado indígena de le conquista, sino que también debe aplicarse al lado español, mestizo, negro... Ver al respecto los trabajos de Solange AlBERRO, Les Espagnols dans la Mexique colonial. Histoire d'une acculturation, París, ed. Armand Colin, 1992 y Carmen BERNAND y Serge GRUZINSKI "La redécouverte de l'Amérique" en L'Homme, 122-124, París, 1992, págs. 7-31, número

\section{R. I., 1996, n. 208}


logía del indio valiente y guerrero, nos pueden conducir a otro escollo que consistiría en hablar de paz donde todavía hay dominación, control, violencia simbólica, imposición arbitraria de un arbitrario cultural, voluntad de asimilación, negación y «negativización» de la cultura ajena; en fin, la existencia de un conjunto de actos, estrátegias, técnicas y tácticas tendentes a la dominación y al sometimiento de un sujeto por otro. Si bien es cierto que a partir de la segunda mitad del siglo xvir yá no se puede hablar de guerra en la frontera y en la Araucanía, trataremos de mostrar que tampoco se puede hablar de paz. El período de guerra-paz de los primeros cien años de la Conquista conduce al establecimiento de relaciones de fuerza que se formalizan en los primeros Parlamentos de Quillín (1641, 1647) y Manquehua (1646), pero en los años siguientes entramos en otro período histórico: las relaciones de fuerza que emanan del primer período de guerra-paz se modifican y se instaura una nueva lógica. La lógica de los primeros tiempos desaparece paulatinamente, dejando atrás la oposición fundamental del primer período, es decir, la oposición guerra-paz.

Se han hecho otras críticas a los Estudios Fronterizos. El historiador chileno Leonardo León ha mostrado en uno de sus trabajos que, dejar de lado la zona pampeana en el estudio de las relaciones hispano-indígenas para privilegiar solamente la frontera del Bío-Bío, impide tomar la medida de la dinámica global de esas relaciones (26). Carlos Lázaro ha mostrado en su

especial que proporciona una buena imagen de los nuevos planteamientos y enfoques de la antropología histórica americanista en Francia.

(26) Leonardo LEÓN SOLIS escribe al respecto: «La historia de las relaciones fronterizas en la Araucanía requiere algunas clarificaciones en lo que respecta al siglo XVIII. En primer lugar, es necesario identificar el ámbito geográfico específico que se envuelve bajo el concepto de frontera. En este caso, la historia que se ha hecho está limitada fundamentalmente a los eventos que tuvieron lugar en la región del Bío-Bío y, en menor medida, el presidio-ciudad de Valdivia. Pero se sabe bien que el ámbito operacional de los araucanos no se restringió a estas dos regiones. Desde fines del siglo XVI existen numerosos testimonios que describen la expansión de las tribus araucanas hacia la Pampa para cazar los ganados cimarrones y robar las estancias que surgían en Mendoza, San Luis, Córdoba, Buenos Aires. En segundo lugar, es necesario enfatizar que, desde comienzos del siglo XVII, los guerreros indígenas abandonaron el antiguo sistema de guerra fortificada y adoptaron nuevas tácticas de confrontación. La guerra de Arauco comenzó 
tesis (27) que los Estudios Fronterizos han olvidado casi totalmente integrar el lado indígena al estudio de las relaciones hispano-indígenas, o mejor dicho, han menospreciado los cambios ocurridos en la sociedad indígena y la influencia que esos cambios tuvieron en la determinación de la política colonial. En cuanto a nosotros, creemos que la idea desarrollada por Villalobos según la cual existieron dos períodos, uno de guerra y otro de paz, es bastante equivocada, por lo que a continuación presentaremos estos dos períodos históricos y desarrollaremos nuestras propuestas al respecto.

\subsection{El diagrama soberano: desde el principio de la Conquista hasta la mitad del siglo XVII}

El rasgo que caracteriza este primer período es el de la guerra violenta y de la paz esporádica; en él se asientan dispositivos de poder tales como la encomienda, la esclavitud, la maloca, el fuerte, la expedición guerrera $\mathrm{y}$, en los primeros tiempos de la Conquista, el requerimiento. Tales dispositivos se fundan en una mecánica que se propone someter a masas y que funciona con un principio subyacente, que podríamos definir como el derecho a matar.

Considerada desde esta perspectiva, la encomienda, típica institución colonial, es una empresa que tiene como meta esen-

\footnotetext{
a extinguirse, pero el conflicto hispano-indígena no desapareció, solamente fue reemplazado por la furia del guerrero de malón que, montado en excelentes caballos, cubierto de coseletes y armado de cuchillo, asolaba las haciendas y villas. Así, la paulatina decadencia de la confrontación formal y el aparente estado de paz que prevaleció en la región del Bío-Bío, fueron eventos locales que influyeron pero no constituyeron el único factor que configuró las relaciones hispano-araucanas. En tercer lugar, se debe tener presente que el territorio indígena del siglo xviII era más grande que la Araucanía histórica y que comprendía no sólo un espacio más amplio, sino que estaba ocupada por un mundo tribal más complejo" (Maloqueros y conchavadores en Araucanía y las Pampas, 1700-1800, págs. 15-16, Temuco, Ediciones Universidad de La Frontera, 1991).

(27) Carlos LAzaro Ávila, La transformación sociopolítica de los araucanos (siglo XVII), Madrid, Departamento de Antropología de España y América, CSIC, 1995.
}

R. I., 1996, n.० 208 
cial juntar bienes y riquezas no a partir del control del cuerpo del indígena, sino de una masa de indígenas; asimismo, no determina una vigilancia continua sobre el cuerpo del indígena, sino un uso discontinuo de su fuerza de trabajo.

La maloca y la expedición guerrera obedecen a un mecanismo de imposición violenta del poder soberano y absoluto. La necesidad de ubicar geográficamente a los indígenas no interviene como modo de vigilancia sobre ellos, sino como instrumento que permite realizar de modo eficiente una empresa discontinua y represiva.

El requerimiento enuncia de manera casi caricaturesca el poder absoluto del soberano sobre masas y territorios indeterminados, así como sobre grupos desconocidos y definidos como vasallos del Rey.

La esclavitud, legalizada y reformulada por varias disposiciones reales, no tiene por objetivo vigilar a los indios sino someterlos para extraerles riqueza en forma de trabajo.

En cuanto al fuerte funciona como enclave en el interior del territorio indígena, como lugar protegido, aislado e inexpugnable, simbolizando el poder español y Real. Es un lugar estratégico desde el que se pueden organizar expediciones guerreras para volver a encerrarse en él. Es un espacio cerrado, monolítico, que impide toda comunicación con los indígenas. Veremos más adelante que esa función y concepción del fuerte irán cambiando para transformarlo en instancia de vigilancia y comunicación.

Este primer diagrama abstracto de poder, que llamaremos soberano, tiene como meta someter a masas por vía de la guerra-paz. A partir de ahí se puede llegar a determinar momentos de paz. Esto significa que, en un momento dado, uno de los actores o los dos deciden parar la confrontación bélica con el objeto de tratar de afianzar las relaciones, de poder que hubieran resultado del período de guerra. Si durante este período transitorio uno de los actores no se encuentra satisfecho del estado del campo de poder que emana del período anterior, puede perfectamente empezar la guerra de nuevo, pero siempre pensando en la paz venidera.

Este marco de análisis nos permite interpretar de manera diferente a lo que hasta aquí se ha hecho el fracaso del inten- 
to de asentar la paz del padre Luis de Valdivia (28). Primero, la derrota del jesuita se puede entender como la imposibilidad de establecer en un sistema soberano mecanismos de poder que obedecen a otra lógica. La voluntad de conquistar a los indios por vía de Parlamentos y Misiones entra en contradicción con el modelo imperante en la época; de modo que los conflictos existentes entre los jesuitas y los otros agentes coloniales como el ejército, los encomenderos, los gobernadores, fueron la expresión de una tensión en el campo de poder colonial. En cierto modo se podría decir que los jesuitas llegaban demasiado temprano con técnicas de asentamiento de paz distintas a las empleadas por los otros agentes. La paz generada por ellos iba a ser diferente a la deseada por los gobernadores y soldados. Se inscribía en otro diagrama de poder y tenía como principio ordenador no aquél definido como soberano, sino uno nuevo, más sutil y menos cruento, una nueva tecnología: la disciplina. Podría decirse que, durante el período de guerra defensiva, tenemos un conflicto entre una mentalidad colonial que empieza a surgir y una mentalidad conquistadora todavía dominante.

El segundo argumento que nos permitiría explicar el fracaso del proyecto de paz del Padre Valdivia lo podemos encontrar del lado indígena. Nos parece poco probable que los indígenas pudieran aceptar y entender que se estableciera un nuevo modelo, cuando los dispositivos antiguos aún seguían vigentes. Los indígenas no podían entrar en una nueva lógica en tanto en cuanto los dispositivos de la esclavitud, la maloca y la encomienda seguían funcionando. Estamos plenamente de acuerdo con Zapater cuando escribe:

(28) Hacemos referencia aquí al período llamado de Guerra Defensiva (1612-1626), durante el cual el Padre Luis de Valdivia trató de entablar relaciones "pacíficas" con los reche. Este intento llegó después de más de 60 años de confrontación bélica entre españoles y reche. Ver al respecto los trabajos de Pinto [3] y Jorge Pinto Rodriguez "Misioneros y Mapuches. El proyecto del Padre Luis de Valdivia y el Indigenismo de los jesuitas en Chile» en Encuentros de Etnohistoriadores, Edición Osvaldo Silva y otros, núm. 1, Universidad de Chile, 1988, págs. 70-92; ZAPATER [16]; LAZARO [27].

R. I., 1996, n." 208 
El misionero [Luis de Valdivia], tenía que encontrar la paz y la conciliación, aunque la realidad lo contradijera y aunque indígenas y españoles no lo entendieran (29).

Añadiremos que, en todo caso, los españoles y los indígenas no lo podían entender porque la lógica desarrollada por el Padre Valdivia era totalmente distinta. No era una lógica de guerra-paz dentro de un esquema soberano, sino una lógica de disciplina-conversión dentro de una máquina mucho más compleja y moderna, que se iba a afianzar en las décadas futuras. Se iba a instaurar una nueva forma de poder y un nuevo tipo de saber. Precursores de esto fueron a nivel de poder la tentativa de transformación de la cultura y a nivel del saber el Arte y lengua de Chile escrito por el Padre Valdivia y publicado en Lima en 1606. Además, hay que señalar que, como ha mostrado Carlos Lázaro (30), los sesenta primeros años de intensa guerra habían generado cambios dentro de la sociedad indígena. En efecto, se había institucionalizado un grupo social, los conas o guerreros, especializados en la guerra o el malón, por lo que el proyecto del Padre Valdivia chocaba también contra la propia dinámica socio-política indígena.

En cuanto al espíritu del proyecto, pensamos que fue precursor de lo que iba a pasar después, durante el segundo período. Luis de Valdivia trata, en efecto, de evangelizar a los indígenas, de dialogar con ellos por vía de los parlamentos y, sobre todo, tiene una visión original de la frontera y de la función del fuerte. Valdivia ya no concibe la frontera como un enclave, sino como una línea de comunicación y de vigilancia; comunicación entre los diferentes puestos españoles, que deben de estar siempre conectados entre sí; vigilancia de los indios amigos, asentados en las proximidades del fuerte. Tampoco éste funciona ya como dispositivo concreto de penetración, aislado, cerrado e inexpugnable, sino como una instancia de visibilidad que se integra como un eslabón a una cadena movediza. Se convier-

(29) Horacio: ZAPATER, «Parlamentos de paz en la guerra de Arauco (1612-1626)", en Araucania, temas de historia fronteriza, Temuco, Ediciones Universidad de la Frontera, 1989, pág. 82.

(30) LAzARO [27]. 
te además en un espacio abierto hacia los indígenas, ya no es el lugar desde el que se emprenden expediciones hacia el territorio indígena, sino un espacio hacia el que se les quiere atraer, con el fin de comunicarse con ellos y tener una idea clara de la organización éspacial de los indígenas asentados tierra adentro. Se trata, pues, de acumular informaciones sobre la estructura espacial y sobre el número de indígenas que viven dentro de los tres futamapu. Resumiendo, se podría decir que los jesuitas tuvieron razón demasiado temprano (31) y que dieron muestras de un espíritu extremadamente moderno para la época. Carlos Lázaro ha señalado en su tesis que:

Valdivia expuso al virrey del Perú que la fortificación del Bíobío no sólo serviría en el futuro como frontera de contención de los ataques indígenas; también actuaría como el punto de partida de las expediciones religiosas que los misioneros jesuitas harían en la Araucanía con el fin de catequizar a los araucanos y convencerlos para que se redujesen a pueblos. En este sentido la propuesta de Valdivia proporcionaba un cariz más activo al proyecto original de Guerra Defensiva ideado por Villela (32).

Creemos que esa faceta "activa» es efectivamente lo que caracteriza la empresa de Valdivia y que las expediciones religiosas lanzadas desde la frontera son, a la vez, una manera de acercarse a los indígenas para evangelizarlos y un instrumento novedoso para obtener informaciones sobre una población todavía poco conocida a principios del siglo XVII.

\subsection{El diagrama disciplinario: desde la segunda mitad del siglo XVII hasta el final del siglo XVIII}

Este segundo período histórico ya no es un período de guerra, pero tampoco es un período de paz, porque una vez abandonado el diagrama soberano, una vez rehusada la guerra

(31) Retomamos aquí una expresión utilizada por ETIEMBLE en Les jésuites en Chine. La querelle des rites (1552-1773), París, ed. Julliard, 1966.

(32) LÁZARO [27], pág. 94. 
y cristalizadas en un tratado de paz las relaciones de fuerza, resultado de esa guerra, se entra ya en otra lógica. La paz consiste en ese momento preciso en el que las relaciones de poder que resultan de la guerra se materializan en una hoja de papel. No decimos que haya existido un cambio brusco de un diagrama al otro. Como señalan algunos historiadores, la segunda mitad del siglo xvil se puede considerar aún como un período extremadamente violento, violento en el sentido de choques bélicos. Pero creemos que, a partir de la segunda mitad del siglo XVII, tenemos ya dispositivos de poder que corresponden a otro diagrama y que obedecen, por tanto, a otro principio. Es decir, se busca someter al indígena por medios que no existían en el período anterior. No se abre un período de paz y de asimilación progresiva y espontánea de los indígenas a la superioridad cultural europea, como afirma Villalobos, pero tampoco es un período de guerra-paz como durante los cien primeros años de la Colonia. En la segunda mitad del siglo XvII aparecen nuevas instituciones, que obedecen a otro modo de organización y que ponen en funcionamiento otro tipo de tecnología.

Los Parlamentos, numerosos a partir de 1655 y casi sistemáticos durante el siglo XviII, tratan de las relaciones entre los dos pueblos. Sin duda alguna, los indígenas supieron utilizar esta institución de manera bastante sutil. Ahora bien, es necesario determinar la función que tenía el Parlamento dentro del nuevo diagrama. Permite, en primer lugar, estar al tanto de lo que ocurre tierra adentro; ofrece también la posibilidad de contabilizar de manera bastante precisa a los indios; permite, además, la regulación del comercio y, por último, da la posibilidad de incentivar a los indios a pedir misioneros. En última instancia, el Parlamento funciona como un nuevo dispositivo de poder que tiene como meta vigilar a los indios. Por falta de espacio no vamos a extendernos sobre los pormenores de los Parlamentos, pero podemos dar un ejemplo para ilustrar la diferencia existente entre un Parlamento de principios del siglo xvil y uno de las postrimerías del mismo siglo. En el Parlamento de Catiray del año 1612, se trata de

(...) no hacer la guerra a los españoles ni robarles animales, devolver los cautivos y aconsejar a otras provincias que hicie- 
ren lo mismo; permitir la entrada de misioneros; consentir que mensajeros atravesasen la provincia y avisar a los españoles la llegada de barcos ingleses (33).

Frente a esto, en el Parlamento de 1671, que se desarrolló en la región del Malleco, se trata de

(...) salir de las montañas; de venir a vivirse a las'poblaciones como estaban antes del alzamiento; estar unidos en sus rancherías, estar un capitán de amigos en sus poblaciones para que los mantenga en paz y justicia; que siempre que hubiesen de salir de su población para otra parte han de dar cuenta a su capitán de amigos para ir y volver limitándoles el tiempo (34).

El Parlamento de Negrete de 1726 establece claramente las normas de un comercio mediante ferias (35), y en el que se sostuvo en Tapihue en 1738 se nota la misma voluntad de controlar el comercio, el desplazamiento y el tiempo de los indígenas (36). Ya en 1716, el gobernador de Chile Gabriel Cano de Aponte había resaltado la importancia de los parlamentos en la vigilancia de los movimientos indígenas; al respecto escribe que tuvo:

... avisos que se continuaban los alborotos de los indios bárbaros de (la frontera) con algunas demostraciones aunque no muy claras de alzarse, y que para desvanecer todos estos aparatos y dejar sosegado el país era el único remedio celebrar parlamento general llamando (...) a todos los caciques y toquis de la frontera (37).

El Parlamento, institución fundamental en las relaciones entre los agentes, es desde ahora un dispositivo de vigilancia. Así, en el de Tapihue de 1774 se trata entre otras cosas de vigi-

(33) ZaPater [29], pág. 70

(34) BNCH. MM, volumen 163, documento 3273.

(35) BNCH. MM, volumen 184, documento 4114.

(36) Idem.

(37) BNCH. MM, volumen 178, documento 3892. 
lar, aunque de manera indirecta, los desplazamientos de los indígenas y, por tanto, el espacio y el tiempo. He aquí lo que escribe el gobernador de la época al respecto:

(...) les propuse y aceptaron el nombramiento de jueces (...) para que celasen las salidas de los mocetones y las entradas de yanaconas, españoles, mulatos y negros con obligación de dar aviso al cacique para su inmediata expulsión y remesa a los comandantes de las plazas cercanas como para el castigo de los que saliesen sin licencia y fácil averiguación de las especies, ganados y animales que llevasen robados, haciéndose de lo contrario responsable el cacique que los permitiese o disimulase o no procédiese a la restitución.

Señala también que se ha llegado al acuerdo siguiente:

(...) que no han de usar (los indigenas) de otros pasos del río Bío-Bío que los que tengo señalados presentándose a los cabos de las plazas que los resguardan con manifestación de los efectos que sacaren de sus tierras y de los que retornasen con sus productos o de los que adquirieren con su trabajo personal en haciendas españolas (38).

Es también un dispositivo que sirve para la cuadriculación y delimitación estricta del territorio indígena. En el Parlamento de Lonquilmo de 1783, se fijaron limites i dependencias territoriales de los Butalmapu $i$ de algunas parcialidades sueltas, según los propios términos del presidente de Chile Ambrosio de Benavides (39).

Esta misma voluntad de vigilar a los indios aparece de manera bastante clara en la real cédula del 20 de diciembre 1674 que pone fin a la esclavitud:

(...) antes de tomar resolución de ponerlos en libertad, se haga matrícula y numeración de todos ellos con relación de sus nombres, edades, tierras de su naturaleza y caciques y títulos de esclavitud con que están poseídos (40).

(38) BNCH. MM, volumen 192, documento 4491.

(39) BNCH. MM, volumen 197, documento 4773.

(40) BNCH. MM, volumen 165, documento 3346. 
El abandono de una institución del antiguo diagrama de poder no se realiza de manera descontrolada y no se puede considerar como un simple gesto humanista; la cancelación de este dispositivo es también el resultado de las necesidades imperantes en el nuevo sistema.

Al lado del Parlamento, o mejor dicho en ósmosis con él, funcionaba la Misión. Este dispositivo podría considerarse como el arquetipo del nuevo sistema de poder que se instauró durante este segundo período. A medida que desaparecía la lógica antigua' y que se modificaban las relaciones de fuerza cristalizadas en la paz, la Misión se afirmó como un instrumento privilegiado de vigilancia y de "disciplinamiento" de los indios. De hecho, en la Misión se trata nítidamente de desplazar al indígena y de apropiarse de su tiempo. El poder que ejercitaba el misionero no era sobre la tierra y sus productos, sino sobre los cuerpos y sobre lo que éstos hacen (41), aplicando aquí una fórmula de Foucault.

A partir de la segunda mitad del siglo Xvil se redactaron una plétora de informes y relaciones de jesuitas y franciscanos, que marcan un nuevo interés por parte de los agentes españoles de aquella época respecto al tema indígena. Asimismo, concomitante al desarrollo de este nuevo diagrama de poder disciplinario, encontramos la gestación de un nuevo saber, que tiende a precisar la identidad individual de cada indígena y a definir con precisión su mentalidad y costumbres. Sólo eligiremos dos ejemplos bastante reveladores de la obsesión de control y vigilancia que animaba a los misioneros.

En 1762, en el momento de fundar una misión franciscana en Rucalgue entre los pehuenches, el vicecomisario de misiones, el padre Gondar, enuncia los puntos siguientes:

- que todos los indios estén prontos y obedientes a las órdenes del padre especialmente en concurrir a misa y a la doctrina cristiana: los casados todos los días de fiesta y los niños y solteros todas las tardes y el que no lo hiciere sea castigado según mereciere su descuido,

- que ningún indio salga de la reducción sin licencia del

(41) Foucault [24], pág. 149.

R. I., 1996, n. ${ }^{\circ} 208$ 
padre y del cacique y estarán obligados a decir a dónde van y a qué negocio salen,

- que de ahí en adelante no se permite a ningún indio el tener más de una mujer,

- que se eviten con todo empeño las públicas borracheras y amancebamientos públicos,

- que se trabaje de comunidad un cerco fuerte para el reparo de las chácaras y se ponga a la puerta un indio que sea de mucha fidelidad y cuidado,

- que se ponga un rancho junto al balseadero y que viva en él un indio de continua, para el reparo de los excesos que se experimentan en la balsa (...),

- que para evitar la incomodidad que se sigue a los indios que viven lejos de la capilla de venir a la misa y doctrina se animen cuanto antes puedan a hacer sus casas junto a la misma capilla y reducirse a pueblo, que es lo que el Rey desea para reconocerlos como fieles y leales vasallos (42).

El otro documento es un Método que deberán observar los misioneros del Colegio de Propaganda Fide de Chillán en la conversión de los indios, fechado en 1766. Este documento enuncia los puntos siguientes concernientes al gobierno temporal:

(...) que los capitanes de amigos no hagan ni deshagan en las reducciones cosa alguna sin consulta y parecer de los padres, como está ordenado justamente por el superior gobierno de este reino, sino que los dichos estén sujetos al dictamen de los misioneros, tanto en exortar a los indios como en reprehenderlos y castigarlos (...) (...) los misioneros no solamente son padres sino jueces y por tanto deben velar sobre aquellos infelizes (acá se trata de los indios) en los espiritual y temporal, procurando defenderlos, ampararlos, corregirlos y castigarlos cuando el caso lo pida, aunque este último siempre debe ser por medio del capitán, o su teniente, de modo que los padres han de mandar la corrección y castigo y después deben servir de padrinos para que se temple el rigor y en esto concibirán los indios el amor que les tienen los misioneros,

(42) "Copia del informe del Padre J. Gondar", 28 de septiembre de 1762, AFC, Asuntos Varios, volumen 1. 
- si sucediese haber algún indio digno de ponerse en prisiones, o por repetición de hurtos, de cosa notable o por continuado amancebamiento o por machitunes (que son los tres delitos más enormes y más frecuentes entre ellos (...) (procurar) que este castigo sea (...) no de azotes (...) sino de cepo y cárcel (...), cuidando también que tales correcciones se hagan dentro de los límites de la misión, sin enviarlos a las plazas inmediatas para que no digan sus parientes que los destierran (...),

- (...) que no entre vino alguno (...).

- Porque conviene mucho a los misioneros saber cuántos indios tiene a su largo, y si viven en la misión, o son los que vagos andan por donde quieren, como hacen algunos, determinamos que en cada misión hagan los padres (...) un padrón de todos los grandes y pequeños pero sea de modo que no lleguen a entenderlo los indios para no darles ocasión de decir que esta diligencia es para hacerlos rehenes y encomendados. - Asimismo se ponga ley inviolable que ningún indio salga de la misión, ni a distintas [partes] ni a los españoles sin licencia de los padres, que deberá ser por escrito pasando a los españoles, para que éstos les den buen pasaje (...),

- (...) que los padres misioneros tengan en cada misión un indio o más que les avisen de las faltas de los otros, y de los enfermos (....) (43).

Dejamos aquí la cita de este documento que, junto con otros, dan la medida de la estrategia empleada por los franciscanos con el fin de "civilizar" al indígena. La "civilización" como forma original de la disciplina en el Chile colonial.

Al lado del dispositivo de la Misión, se desarrollan instituciones que tienden a la "educación» de los indios. La «educación» que significa básicamente lo mismo que evangelización o "civilización", es otra forma de vigilar a los indios. En primer lugar, de modo directo, por la presencia de los indios jóvenes en el Colegio de Naturales de Chillán y en las distintas escuelas de las plazas de Arauco, Nacimiento y Santa Bárbara (44). Pero

(43) “Método que deberán observar los misioneros...», AFC, Asuntos Varios, volumen 2 . Otra copia en el volumen 4 del mismo archivo, con la fecha de 1775.

(44) "Carta del Fr. J. Gondar al Fr. F. Pérez», 9 de julio de 1778, AFC, Asuntos Varios, volumen 4. 
también esta vigilancia se ejercía de forma indirecta, ya que los elegidos eran, en general, hijos de caciques que pudieran influenciar a los miembros de su comunidad en cuanto retornaran a ella. Se puede notar, por otra parte, que el dispositivo de la Misión pudo funcionar, en algunos casos y a pesar de las quejas de los misioneros, en perfecta armonía con el comercio y el desarrollo del peonaje. En efecto, en 1779, el comandante de la plaza de Los Ángeles propuso al gobernador traspasar la Misión de Santa Bárbara a Los Ángeles «por la gran cantidad de pehuenches y llanistas que vienen a comerciar a aquella plaza» (45). En un informe del provincial de los jesuitas, fechado en 1764, sobre el estado de las Misiones en Chile (46) se puede apreciar los vínculos entre éstas y el peonaje, en la medida que la reducción de la Mocha está casi vacía por la migración de los indios hacia las ciudades y las estancias.

Es preciso señalar que la educación de los indígenas a cargo de los franciscanos, a partir de la expulsión de los jesuitas, empezó en los primeros años del siglo xviII. En la misma época, se crearon cátedras de lengua indígena.

El otro dispositivo concreto de poder es el comercio. Como ya hemos dicho antes, estuvo regulado por los Parlamentos y el misionero podía ejercer una vigilancia sobre el que hacían los indios de su reducción. El comercio que se instauró en la sociedad colonial-fronteriza no fue, por lo menos a nivel ideológico, cualquier tipo de comercio, sino que fue regulado y tenía una función precisa dentro del nuevo diagrama. Dos ejemplos nos podrán ayudar a ilustrar lo que decimos. En primer lugar, León ha mostrado cómo la Corona española intervino en los conflictos interétnicos, no con la voluntad de dividir a los indios para reinar mejor -la cautela con la cual los españoles ayudaron a los pehuenches en sus luchas contra los huilliches y llanistas, en la segunda mitad del siglo xviII, constituye una prueba bastante clara de esto-, sino con la idea de poner fin a conflictos que impedían el control del comercio así como de los desplaza-

(45) "Carta del comandante de la plaza de Los Ángeles...», 16 de octubre de 1778, AFC, Asuntos Varios, volumen 4.

(46) "Informe del provincial B. Huerer sobre las misiones de indios...», 28 de diciembre de 1764, AFC, Asuntos Varios, volumen 2. 
mientos de las distintas poblaciones indígenas (47). En segundo lugar, algunos españoles tenían una conciencia bastante clara de lo que se podía obtener por vía del comercio. En 1712, el Provincial de los Franciscanos, Fray Antonio Baeza, escribe al Rey que el comercio y los agasajos constituyen un método bastante satisfactorio de reducir a los indios, citando el ejemplo de la estrategia desarrollada por el Marqués de Baydes en los años 1640 (48). Precisamente el período al cual se refiere el Provincial Baeza es, según nosotros, el momento en el que se transforma el diagrama de poder.

Otro aspecto de este nuevo diagrama fue la implantación de los famosos caciques embajadores en la segunda mitad del siglo XVIII. La idea era tener en Santiago representantes de los cuatro futamapu que tuvieran poder suficiente como para tomar decisiones que comprometieran a la totalidad de las parcialidades indígenas. Esta institución tenía como meta principal vigilar e influenciar a los representantes indígenas con el fin de imponer sutilmente el punto de vista más favorable a las autoridades coloniales. Este intento, como el de los colegios de indios, fracasó. Pero lo que nos importa aquí es que existió y, por tanto, nos permite tener una idea de los dispositivos concretos que se instauraron para someter y dominar a los indígenas. Proporciona también un ejemplo histórico bastante claro de que el poder es mucho más que algo puramente represivo. Por el contrario, el poder es creativo, innovador y no se expresa solamente en la guerra. Por lo tanto, aunque los choques bélicos van decreciendo, ello no significa que ya no existan dispositivos de poder tendentes al sometimiento y a la dominación.

Sólo un ejemplo más: el cargo de capitán de amigos adquiere una nueva dimensión a partir de la segunda mitad del siglo xvir. Su función ya no es solamente la de espía, sino que actúa como vigilante bajo el control del misionero y/o del oficial de un fuerte.

(47) Leonardo LEÓN, "La corona española y las guerras intestinas entre los indigenas de Aracaunía, Patagonia y las Pampas, 1760-1806", en Nueva Historia, núm. 5, Londres, 1982, págs. 31-67.

(48) "Carta del Fr. A. Baeza al Rey», BNCH. MM, volumen 175, documento 3800 .

R. I., 1996, n." 208 


\section{CONCLUSIÓN}

Para terminar, sólo queremos señalar lo siguiente: en primer lugar, aunque no hayamos podido abordar aquí de manera amplia las contradicciones que existían en la sociedad colonialfronteriza y de tierra adentro, hemos tratado de determinar la dinámica global en la que estas contradicciones se inscribieron. En segundo lugar, pensamos que la guerra y la paz deben analizarse en términos de sistema, ya que cuando dejó de existir una lógica guerrera estricta, que trataba de someter al otro por medios violentos, entramos en otro sistema que no podemos definir exactamente bajo el término paz; la paz es el momento preciso en el que cristalizan las relaciones de fuerza que han emergido de la guerra. Una vez que se ha salido de la lógica de guerra-paz y que se han producido modificaciones en las relaciones de fuerza formalizadas en la paz y se han transformado los dispositivos de poder, entramos en un nuevo período en el que aún continúan existiendo relaciones de poder, voluntad de dominación y estrategias de sometimiento.

Obviamente, este nuevo período no es un período guerrero, sino que se trata del asentamiento de un nuevo diagrama, un nuevo tipo de poder. A partir de aquí, podemos adelantar que, lo que ocurrió en la segunda mitad del siglo XvII y a todo lo largo del siglo XviI, no fue ni una guerra ni una paz, sino una nueva gestión de los campos de poder. Se estableció así una nueva tecnología de poder que tenía como meta normalizar, contabilizar, civilizar, en una palabra: disciplinar al indígena. El siglo XVIII es el siglo de la gran cuadriculación de la "Araucanía" y de los mapuche. A partir de esto, pero sólo de esto, no resulta contradictorio e ilegítimo hablar de etnocidio o de empresa "etnocidiaria».

Nuestro principal objetivo ha sido mostrar que lo que se asienta a partir de mediados del siglo xvir es mucho más que la paz; son técnicas polimorfas de sometimiento. No se trata de un tipo de poder puramente represivo como aquél que se ejercita durante un período de guerra-paz, sino de un tipo de poder creativo, que genera un nuevo saber encaminado a registrar, indagar y verificar. En definitiva, lo que surge durante este nuevo período histórico, es una nueva forma de hacer la guerra, una guerra silenciosa: la política. 
En esta segunda parte no hemos tratado del lado indígena. Mejor dicho, no hemos abordado explícitamente la importancia que tuvieron la resistencia y los cambios sociopolíticos de la sociedad indígena en las transformaciones de los dispositivos de poder utilizados por los españoles. Pero creemos que, aunque no mencionamos este factor de manera explícita, la presencia indígena se deja sentir a lo largo de todo lo que hemos revisado como dispositivos. Es decir que si, como hemos visto en la primera parte, los cambios ocurridos entre los reche fueron determinados por el contacto, es cierto también que las transformaciones de los dispositivos de poder obedecieron a una urgencia concreta y se desarrollaron dentro de un contexto histórico apremiante.

Si bien es cierto que el diagrama de poder obedece a un principio abstracto, los dispositivos concretos tratan de dar una respuesta adecuada a un contexto socio-histórico determinado. A partir de ahí, creemos que habría que reflexionar sobre la influencia que tuvo el contacto con el Otro del Nuevo Mundo sobre la concepción acerca de la alteridad en el Viejo Mundo. Habría que ampliar la reflexión sobre la interacción de los distintos dispositivos de poder entre el Nuevo y el Viejo Mundo. Pero si nos atenemos por el momento al caso del centro-sur de Chile, podemos ver que la resistencia indígena tenía como pre-condición un proceso largo de transformaciones socio-políticas y culturales. De suerte que, a pesar de la extraordinaria creatividad de los españoles para someter a los indígenas, estos últimos siempre pudieron permanecer como entidad específica, pero al precio de una tremenda reestructuración. La ironía de esta historia es que los españoles de tanto querer someter a una población terminaron generando una nueva entidad e identidad étnica (49).

(49) Este tema de la creación de nuevas entidades e identidades étnicas como resultado del contacto hispano-indígena tiende a desarrollarse desde hace algunos años en los trabajos de antropología histórica. Un buen ejemplo de esta perspectiva en términos de construcción y transformación de la conciencia y de la identidad étnica se encuentra en lo que escribe Manuel MARZAL del indigenismo durante el período colonial: "El sistema de reducciones, aunque facilitará la explotación colonial y significará una 'desestructuración' de la organización social de las diferentes etnias andinas... será el crisol de una nueva conciencia étnica... Como observa Pablo Macera: 
The mapuche or Araucanians of South-Center Chile are famous for their ferocious and plurisecular resistance to the Spanish invader. This traditional image of the indomitable, brave and warrior Indian and the vision of the Colony as a permanent period of war have been criticated by the Estudios Fronterizos. This historical movement who emerged in Chile at the beginning of the 1980's proposed a new interpretation of the "encounter between Spanish and southern indigenous people in order to take into account the pacifical contacts and the frontier relationships. Nevertheless, we will demonstrate that in their will to escape from the warfare paradigm, the Estudios Fronterizos have made another mistake which consists to speak about peace when it seems more appropriate to see transformations into the power devices. What is more, we will understand that their ethnocentrical point of view impeded them to see one of the most important concequence of the conquest: the emergence of a new ethnical group and the construction of a new mapuche identity through a long process of ethnogenesis which changed the reche of the 16 th century into the mapuche of the 18th century.

'Los españoles, sin querer, hicieron de los indios una sola nación'» (Historia de la antropología indigenista: México y Perú, Barcelona, Anthropos, Editorial del Hombre, 1993, pág. 45, la edición, Lima, 1981). Se encuentra también esta idea en el estudio de François-René Picón, Pasteurs du Nouveau Monde: Adoption de l'élevage chez les indiens guajiros, París, Ed. de la Maison des Sciences de l'Homme, 1983. Señalemos también que el estudio realizado por Isabelle COMBÉS y Thierry SAIGNES sobre los chiriguanos constituye un ejemplo absolutamente magistral de un análisis en términos de construcción socio-histórica de la identidad (Cfr. Alter Ego: Naissance de l'identité Chiriguano, París, Ed. École des Hautes Études en Sciences Sociales, 1991). A pesar de que este nacimiento de la identidad chiriguano sea el resultado de una dinámica inter-indígena, pensamos que el enfoque de esos dos estudiosos representa un excelente ejemplo del camino a seguir por una antropología preocupada por desprenderse del marco interpretativo de tipo substantivista. Hay que señalar, finalmente, que esta reflexión sobre la etnicidad, la construcción de la identidad y la emergencia de entidades sociopolíticas se ha ido desarrollando desde hace años en otras disciplinas y áreas culturales. Véase al respecto los estudios siguientes: J. L. AMSELLE y E. M'Bokolo (bajo la dirección de), Au coeur de l'ethnie. Ethnies, tribalisme et Etat en Afrique, París, Ed. La Découverte, 1985; Jackie AssAYAG, "Déjà lu. L'héritage colonial de l'anthropologie en Inde», en L'Homme, 137, París, 1996, págs. 205-209, y Ph. Poutignat y J. Streiff-Fenart, Théories de l'ethnicité, París, Ed. PUF, 1995. 


\section{LOCALIZACION DEL TERRITORIO RECHE-MAPUCHE EN EL CENTRO-SUR DE CHILE} (SIGLOS KUII-KUIII)

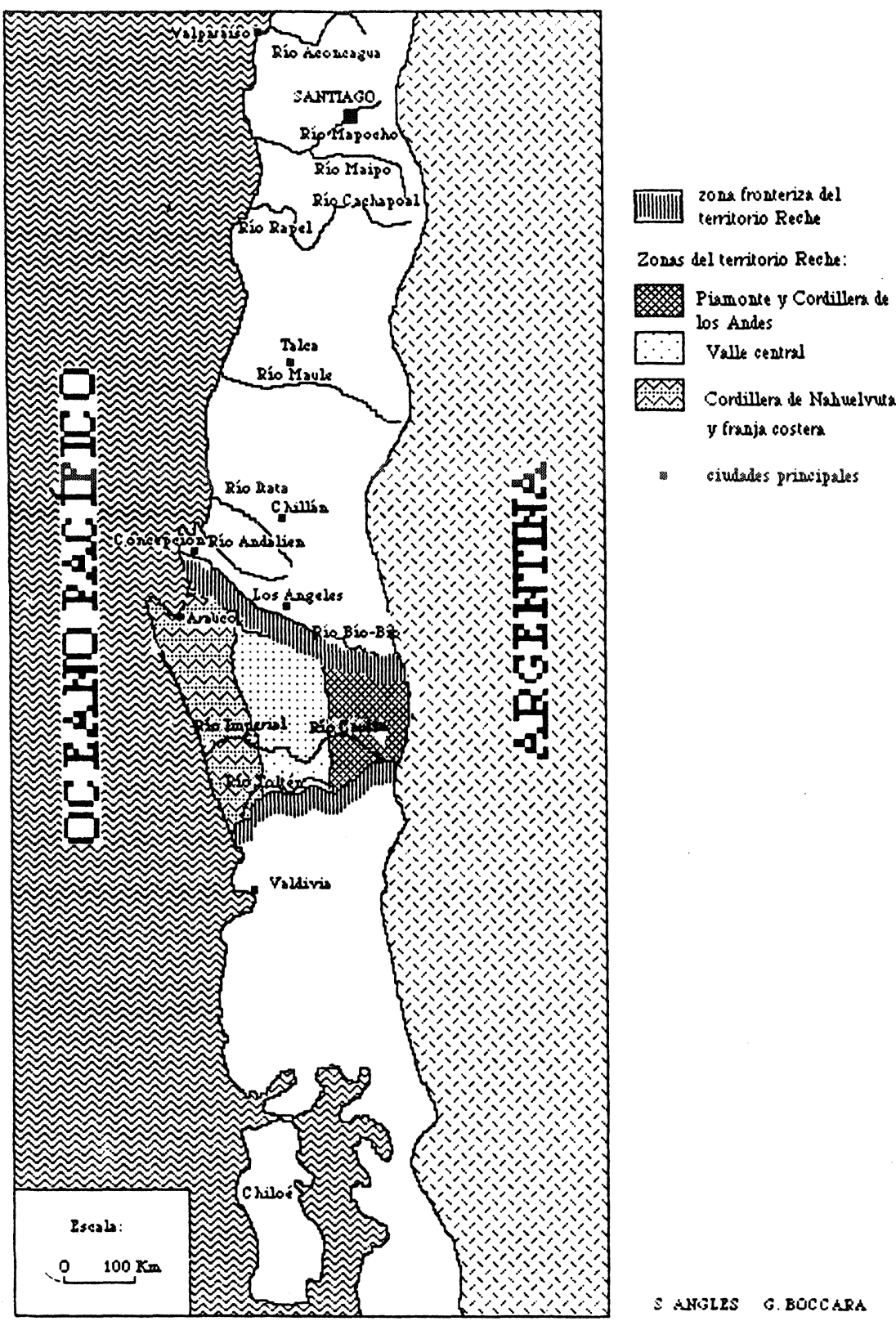

R. I., 1996, n.o 208 
RESISTENCIA/TRANSCULTURACIÓN RECHE-MAPUCHE CENTRO-SUR CHILE (XVI-XVIII) 695

LOCALIZACION DEL TERRITORIO RECHE-MAPUCHE EN EL CONJUNTO CHILENO (SIGLOS KUII-KUIIII)

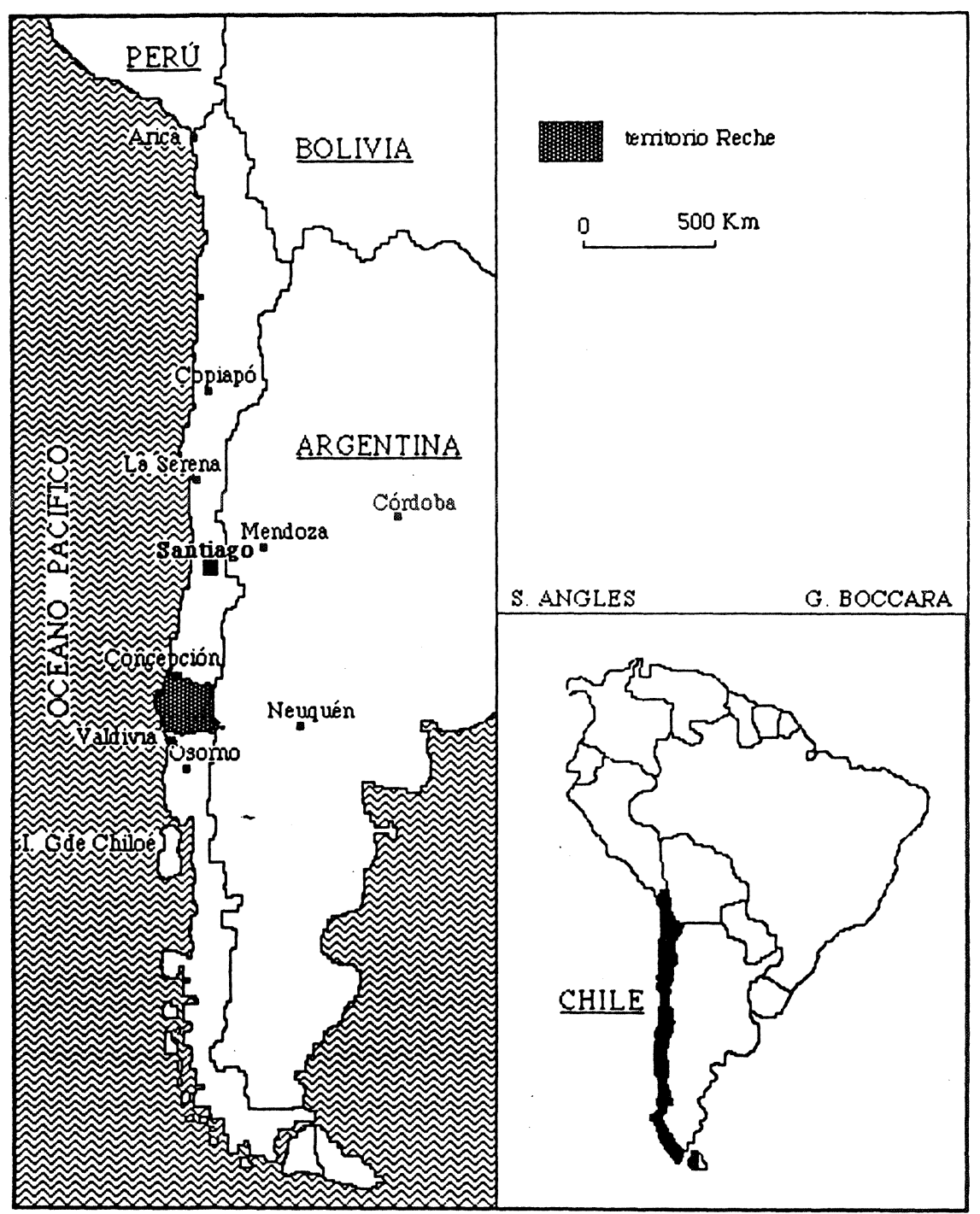

R. I., 1996, 11." 208 